\title{
Application of mathematical models for improvement of "cloud" data processes organization
}

\author{
Boyko N. \\ Lviv Polytechnic National University \\ 28a S. Bandera str., 79013, Lviv, Ukraine
}

(Received 30 December 2016)

\begin{abstract}
The paper presents the main approaches to distributed organization of data in computer networks processing and organization of distributed applications. The main approaches to organization of distributed computing systems are described. The conception of GRID computing and comparative analysis of technologies and architectures of "cloud computing" and GRID systems creation are outlined. The estimations of the advantages and disadvantages of computing processes in web-systems are presented. The analysis of analytical models of cloud computing nodes is made. New conceptions of distributed web-systems development with NoSQL using are described. The article dwells upon the main methods of data processes organization in distributed networks. Mathematical models that allow to study the way of computations organization in the nodes of "cloud" are described. Modeling of nodes operation with the help of public service system is presented.
\end{abstract}

Keywords: information system, database, web-service, cloud computing, information flows, information processes, data processes.

2000 MSC: 94-06, 94A15, 94D05

UDC: 519.72

\section{Introduction}

New projects of management systems informatization are always created with a certain pre-analysis and quality assessment of existing software products. Prospective analytical studies are limited to the required industry domain in which, according to certain goals, information flows are organized in a certain way. As a result, when processing the same datasets there is a large array of information processes that are duplicated. But these processes are incompatible, when the question about the integration of information resources is presented, for example, to implement a horizontal information processes. Despite this organizational structure, there are other projects of information or data analytical systems that are created to achieve the same goals.

Also in practice, data mining techniques and intellectual data analysis are widely used. Therefore, there is a need for sharing of relevant tools and developed business processes in distributed network data structures.

Specific solution for a specific distributed data organization may be the creation of an abstract level of information resources architecture for joint use. This architectural level should cover the issues of interconnection, data integration and information access or content management information flows. This level can support transactional execution and to provide the necessary information and communication services. It can serve as a certain integral for information systems a certain level of control. Therefore, this architecture can become a modern architecture, which is capable of organizing distributed computations with use of computing networks (metacomputing). To support this, we need joint and coordinated use of diverse resources in dynamic, distributed virtual organizations, "cloud computing" (cloud computing).

Cloud computing is the successor of GRID technologies of resources integration. Their rapid development was facilitated by: the proliferation of personal computers, the development of the Internet and packet data transmission technology. 
The use of such technologies gives user the access to own data without infrastructure management or operating system or software with which it works. The use of cloud computing provides a virtualization of information processes, data availability, easy to administer software assets, and elastic scaling.

"Cloud computing" provides such information technologies as "Software as a Service" or "SaaS", "Infrastructure as a service", "Infrastructure as a Service" or "IaaS", "Platform as a Service" or "PaaS" etc.

The deployment model of the application SaaS provides the end user with the application via the network, and most often through the Internet browser.

The model of providing computing infrastructure as a service IaaS enables to get programme resources in the form of outsource services.

The model of providing a computing platform as a service in the network PaaS allows users of cloud computing to take advantages of the processing power, software and data storages which through some virtualization technologies and a high level of abstraction are in the form of services.

To manage all infrastructure elements the specialized software of secondary or intermediate level, which is also called "middleware control" is used. It gives key services such as: consistency, transacting, multiple flows and messaging for applications built on the basis of service-oriented architecture (SOA). "Middleware control" also includes the security services and software high availability.

\section{Technologies of the cloud computing creation in distributed systems}

The application of GRID technologies of distributed computing has developed its own standard OGSA (Open Grid Services Architecture) [8], which positions itself as a powerful tool of all possible distributed technologies such as web, peer-to-peer networks, clusters and distributed computing, virtualization technologies. In addition to these distributed technologies GRID technologies have differences [3], they coordinate the information flows that are not managed centrally, they use open standards protocols and interfaces of general purpose and certain levels of service quality are provided.

There is a difference between "cloud computing" and GRID computing. In "cloud computing" platforms are focused on the approach of "everything as a service". They focus on the paid provision of information resources to the end user. GRID technologies provide the advantage of intermediate software, which is presented as open initial codes or as ready packages.

In general the standard architecture of "cloud computing" system is integrated from three layers. The first one - "cloud computing and data" - are technical and hardware and data transmission networks on the basis of which the tasks of the user are carried out. The user directly refers to the "information cloud", that is, to information database with NoSQL interface. A closing process is the acquisition of knowledge in the "cloud of knowledge", where high level applications are carried out, which provide information processes of the semantic and intelligent decision making.

Using of cloud computing allows to ensure organization and integration of distributed incompatible computing powers, to support intermachines links providing the creation of computational and informational resources for their general use.

\section{The indices of the cloud computing efficiency organization}

The main element of the "cloud computing" architecture is systematized metadata that describes the entities for their automatic interaction. These metadata gives individual "agents" of each newly created entity. Intermachine cooperation processes and support of agreements between separate entities are controlled by "brokers". Network agents are responsible for routing optimization and support of expected service quality level.

To assess the advantages and disadvantages of computing processes in the cloud we should use the efficiency indices of their work. They can be divided into two large groups: indices based on the assessment of average or maximum residence time (delay relative to valid dates) of tasks in the 
system [11] and metrics based on the rating of productivity of structural and functional components. The latter are characterized by different factors: the number and load of the involved resources, their downtime, frequency of conflicts when accessing shared computing resources $[11,12]$ etc.

The first group of indices clearly determines the effectiveness of computing. In this case, the cloud node service is taken into consideration, that is, the database with the NoSQL interface. The rules of node behavior regarding the tasks depend on the type of failure of hardware in a particular place.

The database acts as a service of cloud computing node and it is designed according to the highest requirements for reliability of its functioning. The task of nodes modeling is solved to identify the most effective organization of the computing process, to ensure the lowest fall in productivity of database work if there are any failures in the work of IS. In the work $[11,15]$ and some other researches it is proposed to evaluate the efficiency of web services computing processes organization by using the following functionals (1)-(2):

$$
\begin{gathered}
C^{S}=\sum_{i=1}^{n} \alpha_{i} \lambda_{i} \nu_{i}^{S}, \\
C^{\prime S}=\sum_{i=1}^{n} \alpha_{i}^{\prime} \lambda_{i} P_{i}^{S} \quad\left(>D_{i}\right),
\end{gathered}
$$

where $\alpha_{i}, \alpha_{i}^{\prime}$ are respectively the penalties for one of time unity of the $\mathrm{i}$-th type task in the system and its loss due to exceeding the allowed directive time $D_{i} ; \lambda_{i}$ is the intensity of the $\mathrm{i}$-th flow task; $\nu_{i}^{S}$ is average time of the $\mathrm{i}$-th type task presence in the system; $P_{i}^{S}\left(>D_{i}\right)$ is the probability of the i-th type task expectancy over the acceptable directive time $D_{i} ; n$ is the number of task types; $S$ is a parameter that characterise the variant or a way of computing process organizing; $C^{S}, C^{\prime S}$ are respectively, the average total fines for tasks presence in the web system and their losses in the result of exceeding the acceptable directive time.

Efficiency index (1) is based on the assumption that the task is devalued proportionally to the time of its presence in the web system, efficiency index (2) - on the assumption that in excess of some time of expectancy the task loses its value immediately.

There is also a general index of computational processes efficiency (3):

$$
C_{T_{V R D}}^{S}=\sum_{i=1}^{n} \alpha_{i}^{\prime} \lambda_{i} T_{V R D}^{S},
$$

where $T_{V R D i j}=\frac{1}{N_{i}} \sum_{i} t_{V R D i j}$ is the average value of relative delay of the $\mathrm{i}$-th type tasks in a web system;

$$
t_{V R D i j}=\left\{\begin{array}{lll}
0, & \text { if } \quad t_{I T i j} \leqslant T_{A I i j}, \\
\frac{t_{I T i j}-T_{A I i j}}{T_{T A W i j}-T_{A I i}}, & \text { if } \quad T_{A I i j}<t_{I T i j}<T_{A I i}, \\
1, & \text { if } \quad t_{I T i j} \geqslant T_{A I i},
\end{array}\right.
$$

where $t_{V R D i j}$ is relative delay of $j$-th task of $i$-th type in the web system; $t_{I T i j}$ is interruption time of $j$-th task of $i$-th type in the web system from the moment of receipt until the end of his service; $T_{A I i j}$ is admissible interruption time of $j$-th task of $i$-th type in the web system, when its value is not reduced; $T_{T A W i j}$ is time after which $j$-th task of $i$-th type is completely devalued; $N_{i}$ is number of $i$-th type tasks, received by the web system during the time $T$.

The basis of the efficiency index (3) is formed by the assumption that value of information flow that is received by the database node, until certain directive time $T_{A I}$ remains constant and since its excess is linearly reduced until the full depreciation in the moment of time $T_{T A W}$. Therefore, it is easy to show that when the efficiency index $Y_{A I i}=T_{T A W i}=D_{i}$ (3) takes the form of expression (1), and when $T_{A I i}=0$ and $T_{T A W i} \gg \nu_{i}$ the expression (2). By using formulas (1)-(3), we can estimate 
the efficiency of the S-th way of web system computing process organizing with the NoSQL interface compared with the $\mathrm{q}-\mathrm{m}$ ratio:

$$
K^{S, q}=\frac{C q}{C^{S}}
$$

where $K^{S, q}$ is efficiency index.

Problem when comparing benefits obtained with $S$-th method of computer processing organization in web-systems, with additional computing resources costs for the implementation of this method is considered to be the disadvantage of the efficiency index (4). Therefore, more obvious and convenient index for assessing the effectiveness of the organization of the computational process is advantage of equivalent productivity, the essence of which is manifested in the following. The $S$-th way of web system computing process organization reduces the amount of total costs compared with q-m method in $K^{S, q}$ times. The same result can be obtained by q-m method of organization of the computational process, if you increase the productivity of the node. Therefore, the efficiency index of the organization of the web systems computational process can serve as such a relative increase in productivity of the node and decrease of the solution time of all tasks $E^{S, q}=\frac{T_{i}^{S}}{T_{i}^{q}}$, where $C^{q}\left\{\frac{T_{i}^{S}}{E^{S, q}}\right\}=C^{S}\left\{T_{i}^{S}\right\}, T_{i}$ is the solution time of the i-th task in the node.

The most efficiency index of the web-system computational process organization is its actual productivity, which is calculated by (5):

$$
\Psi=\sum_{i=1}^{N} u_{i} c_{i},
$$

where $N$ is the number of processors in the system; $c_{i}$ is $i$-th processor speed of operation; $u_{i}$ is $i$-th processor use index.

For homogeneous media (5) web-system productivity is transformed into the total utilization of processors $G=\sum_{i=1}^{N} u_{i}$.

One of the reasons that reduces the productivity of web systems node, is the emergence of conflict situations in which two or more information processes simultaneously require the same computing resource. To assess the impact of conflict on the effectiveness of the organization of the web-system computational process the following indicators (6)-(7) are used:

$$
\begin{aligned}
& \delta=\left(1-\frac{\psi}{\psi_{0}}\right) 100 \%, \\
& \delta=\left(1-\frac{G}{G_{0}}\right) 100 \%,
\end{aligned}
$$

Where $\psi_{0}, G_{0}$ are respectively, the actual node productivity and the total utilization coefficient of resources without conflict situations accounting.

The value of the efficiency index (6)-(7) express the web system productivity loss with NoSQL interface (in percentage) in the node, which is caused by emergence of collisions between information processes.

\section{The application of analytical models of cloud computing nodes}

Various modes of calculation organizing in the web-systems cloud computing nodes allow to explore a mathematical model. Therefore, we consider the modeling of nodes with the influence of the unnecessary distractions of computing resources in the system. Each node is modeled by Queuing system (QS) [16]. Fig. 1 shows the structure of the QS, where its main elements are: the incoming flow of requests $A$; queue $Q$; the priority service discipline $(S D)$, which determines the order of applications selection from the queue; the attendant device $P$. System functions are the following: the formulation 
of requests in the queue, selection from the queue of the application that is subject to priority service and its maintenance. The output of device $P$ is presented by the output flow $(O F)$.

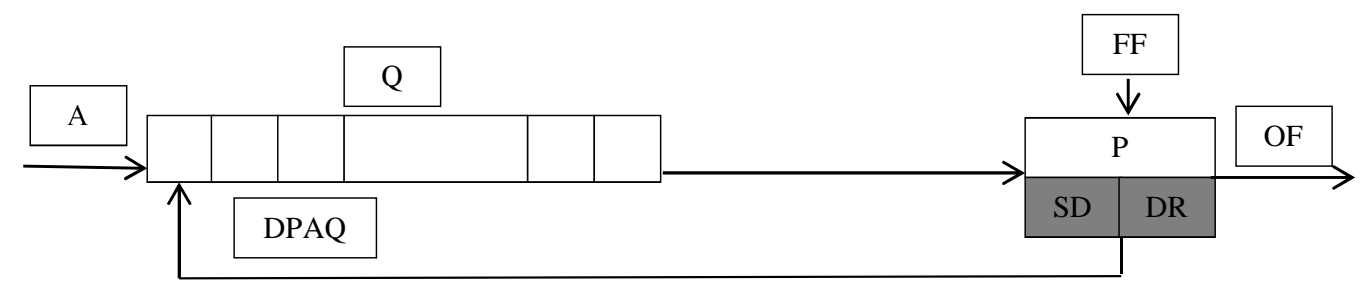

Fig. 1. QS structure, that models the node computing resource.

Operational nodes are characterised by unproductive costs of web systems computing resources. This distraction of resources in general have random nature and within the framework of the queueing theory that studies systems and networks of mass service, and they can be interpreted by flow failures $(F F)$ of operating devices, and their duration by the time of its recovery. After the restoration of operating device, which is refused the request processing starts in accordance to the discipline of recovery $(D R)$. Failures of the operating device cause an increase in the number of unattendant applications, the growth of the queue of applications and further delays in their service.

Due to random nature of the applications service processing, these time delays for certain kinds of processes can be very significant that will have a significant impact on the effectiveness of the organization of the computational process in web systems. One possible way of adapting the system to wastage of computing resources is the introduction of the appropriate discipline of priority applications in the queue $(D P A Q)$ from various processes during the distraction of resources. Such regulation of the flow streams can be achieved through feedback of the resource with applications sources or by closing the queue.

We formulated the tasks in the following way. The input of single-channel queue system with waiting receives Poisson flows $N$ of applications with different intensity $\lambda_{i}, i=\overline{1, N}$. Flows are renumbered in the queue of decreasing importance of the applications, that is the applications of the $i$-th flow have the $i$-th priority in service. The service time of requests is a random variable with distribution function $B_{i} t$ and two infinite moments $b_{i}$ and $b_{i}^{2}, i=\overline{1, N}$.

The attendant device is unreliable and may be disabled according to Poisson law with parameter $\lambda_{0}$. The recovery time of the device is a random variable with the distribution function $B_{0} t$ and two finite moments $b_{0}$ and $b_{0}^{2}$. The device may be damaged as during maintenance of applications (there are two possible cases: the applications are returned to the queue; requests are lost), and in the free state. During the recovery period of the attendant instrument the application of some flows are accepted in the queue and others are not accepted. This condition is given by matrix - the raw of coefficients $n_{i}$, $i=\overline{1, N}$, where $n_{i}=1$ in the case if the applications of the $i$-th flow are accepted in the queue and $n_{i}=0$ if applications get deny in service.

After the restoration of attendant device two disciplines of service restoration are posible: from higher priority applications and applications, the service of which was interrupted by device failure (in case when they are not lost during a failure). It is needed to determine the following characteristics of requests servicing: $w_{i}$ is average expectancy time of servicing beginning of the $i$-th flow requests in the $i$-th queue; $v_{i}$ is the average time of presence of the $i$-th flow applications in the system; $q_{i}$ is the average number of requests of the $i$-th flow in the $i$-th queue; $l_{i}$ is the average number of requests of the $i$-th flow in the system.

The combination of service discipline with one of the disciplines of renovation of service after restoring of the device that was disabled, and the behavior of the application, the service of which was interrupted by the failure, determined the conditions of individual tasks for the priority QS. Analytical models for relative, absolute, mixed and combined priority disciplines are developed and allowed us to obtain the final expression for the desired service features of the applications in web systems. 
Characteristics of service requests in the constant mode are linked by Little formulas that for the systems with priority applications acceptance in the queue during recovery of the device, have the next form (8):

$$
l_{i}=\lambda_{i}^{*} \nu_{i}, \quad q_{i}=\lambda_{i}^{*} w_{i},
$$

where $\lambda_{i}^{*}=K_{r} \lambda_{i}\left(1+n_{i} \rho_{0}\right)$ is the acceptance intensity of the $i$-th flow requests of in the QS taking into account the discipline of admission in line during the recovery of device; $K_{r}=\frac{1}{1+\rho_{0}}$ is the probability that the attendant device is in good condition; $\rho_{0}=\lambda_{0} b_{0}$ is "loading" of system by failures.

The condition for the constant mode in systems of this class without loss is $\sum_{i=1}^{N} \rho_{i}^{*}<K_{r}$, where $\rho_{i}^{*}=\lambda_{i}^{*} b_{i}$ is the probability of device involevement in $i$-th flow request servicing.

\section{Analysis of service indices cloud computing nodes in web-systems}

Let us analyze the expressions obtained to calculate the average waiting time of the service beginning for certain application that enters the system of the $j$-th flow, $j=\overline{1, N}$, in explicit form for different types of the QT, from which it is easy to obtain other characteristics.

System with relative priorities and resumption of demand service, service which was interrupted due to the failure of the system (9)

$$
\begin{aligned}
w_{j}= & \frac{1}{2\left(K_{r}-R_{j}\right)\left(K_{r}-R_{j-1}\right)} \\
& \times\left[n_{1} K_{r} \lambda_{0} b_{0}^{(2)}+\sum_{i=1}^{N} \lambda_{i} b_{i}^{(2)}\left(1+n_{i} \rho_{0}\right)+K_{r} \lambda_{0} b_{0}^{(2)} \sum_{i=2}^{j}\left(n_{i}-n_{i-1}\right)\left(K_{r}-R_{i-1}\right)\right]
\end{aligned}
$$

where $R_{j}=\sum_{i=1}^{j} \rho_{i}^{*}$.

Here is a system with relative priorities and resumption by service requests of higher priority systems (10):

$$
\begin{aligned}
w_{j}= & \frac{K_{r}}{\left(K_{r}-R_{j}\right)\left(K_{r}-R_{j-1}\right)}\left\{n_{1} K_{r} \sigma_{0}+K_{r} \sum_{i=1}^{j} \sigma_{i}+K_{r} \sum_{i=j+1}^{N} \rho_{i}^{*} \Delta_{i}^{*}+\sigma_{0} \sum_{i=2}^{j}\left(n_{i}-n_{i-1}\right)\left(K_{r}-R_{i-1}\right)\right. \\
& \left.+\frac{1}{K_{r}} \sum_{i=2}^{j}\left[\rho_{i}^{*} \Delta_{i}^{*}-\sigma_{i} \overline{P_{D i s}}\left(b_{i}\right)\right] R_{i-1}\right\}
\end{aligned}
$$

where $\sigma_{0}=K_{r} \rho_{0} \Delta_{0} ; \sigma_{i}=\rho_{i}\left(1+n_{i} \rho_{0}\right) \Delta_{i}\left(1+\rho_{0}\right) ; \Delta_{0}=\frac{b_{0}^{(2)}}{2 b_{0}}$ is average time before device resumption, that stopped operation; $\Delta_{i}=\frac{b_{i}^{2}}{2 b_{i}}$ is average time of finish service of application of $i$-th flow without attendant device failures accounting; $\Delta_{i}^{*}$ is average time of device that fulfill the service of application of $i$-th flow and resumption after failure during the finish service of this application;

$$
\overline{P_{D i s}}\left(b_{i}\right)=1-\frac{P_{D i s}\left(b_{i}\right)}{K_{r}} .
$$

System with absolute priorities has such view (11):

$$
\begin{aligned}
w_{j}= & \frac{K_{r}}{2\left(K_{r}-R_{j-1}\right)\left(K_{r}-R_{j-1}\right)} \\
& \times\left[n_{1} K_{r}^{2} \lambda_{0} b_{0}^{2}+\sum_{i=1}^{j} \lambda_{i} b_{i}^{(2)}\left(1+n_{i} \rho_{0}\right)+K_{r} \lambda_{0} b_{0}^{2} \sum_{i=2}^{j}\left(n_{i}-n_{i-1}\right)\left(K_{r}-R_{i-1}\right)\right] .
\end{aligned}
$$


In systems with mixed priorities neighbouring flows of applications are combined into $M$ groups, between which there is an absolute, and inside each one the relative priority of the service. In this case, each m-th group of the application flows contains flows with numbers from $S_{m-1}+1$ to $S_{m}, m=\overline{1, M}$. Unlike systems with absolute priority, the application of the $j$-th flow of the m-th group that is input to the system must wait in the queue of finish service of requests from flows with numbers from 1 to $S_{m}$. Its maintenance can be interrupted by receipt of applications of high priorities in the case that $j>S_{1}$ (in this case the total flow of requests that interrupts its service includes flows numbered from 1 to $\left.S_{m-1}\right)$.

Therefore, the equation for average waiting time of the beginning of service for system with mixed priorities and resumption of application service, service of which was interrupted by the failure, takes the following form (12):

$$
\begin{aligned}
w_{j}^{m}= & \frac{K_{r}}{2\left(K_{r}-R_{j}\right)\left(K_{r}-R_{j-1}\right)} \\
& \times\left[n_{1} K_{r} \lambda_{0} b_{0}^{(2)}+\sum_{i=1}^{S_{m}} \lambda_{i} b_{i}^{(2)}\left(1+n_{i} \rho_{0}\right)++K_{r} \lambda_{0} b_{0}^{(2)} \sum_{i=2}^{j}\left(n_{i}-n_{i-1}\right)\left(K_{r}-R_{i-1}\right)\right] .
\end{aligned}
$$

In the same way the expression for system with mixed priorities and resumption of application service of higher priority systems will also change.

In the system with the combined priorities the service time of all requests, with the exception of requests of the first flow is divided into two segments (stages): on the first one there is an absolute priority, on the second one - relative. Therefore, the duration of the first stage of $k$-th flow application maintenance $z_{i, k} ; i=1, k-1 ; k=\overline{2, N}$ is a constant value, while on the second stage the duration of applications service depends on the discipline of service resumption. Thus, the expression for $w_{j}$ for the system with combined priorities and resumption of application service, service which was interrupted by failure is presented in the following form (13):

$$
\begin{aligned}
w_{j}= & \frac{K_{r}}{2\left(K_{r}-R_{j}\right)\left(K_{r}-R_{j-1}\right)} \sum_{i=1}^{j}\left[K_{r}^{2} \lambda_{0} b_{0}\left(n_{i}-n_{i-1}\right)+\lambda_{i}\left(1+n_{i} \rho_{0}\right) b_{i}^{(2)}+\sum_{k=i+1}^{N} \lambda_{k}\left(1+n_{k} \rho_{0}\right) x_{i k}^{(2)}\right. \\
& \left.-\sum_{k=1}^{N} \lambda_{k}\left(1+n_{k} \rho_{0}\right) x_{i-1, k}^{(2)}+\sum_{k=1}^{i-1} P_{i k}\left(2 b_{k}-z_{i k}\right)\right]\left(K_{r}-R_{i-1}\right)
\end{aligned}
$$

On the basis of the same principle it is possible to derive an equation for systems with combined priorities and resumption of service requests with a higher priority. A distinctive feature of the priority systems with the loss of applications is the loss of applications, service of which was interrupted by the failure of the device. Therefore, the device employment probability with service of requests of the $i$-th flow $\rho_{\text {depri }}^{*}=\lambda_{i}^{*} b_{\text {depr } i}$, where $b_{\text {depri }}$ is determined by the formula $b_{\text {depr } i}=\int_{0}^{\infty}\left[1-B_{j}(t)\right] e^{-\lambda_{0} t} d t$, where $\left[1-B_{j}(t)\right]$ is the probability that at the time the application of the $j$-th flow will be not operated by device; and $e^{-\lambda_{0} t}$ is the probability that at the time $t$ any rejections will not happen. By analogy with the priority systems without losses can be obtained in explicit form: expressions for $w_{j}$ for systems with losses of applications with relative, absolute and mixed priorities in the service.

Fig. 2 illustrates the dependence of the length of the queues of the requests with the lower (curve 1) and higher (curve 2) priorities from the failures intensity of the operating device $\lambda_{0}$, for double priority systems with relative priorities and continuous replenishment mode of queue by requests of high priority during the recovery period of the device.

The calculation was performed for the following values of parameters:

$$
\rho_{1}=\rho_{2}=0.4 ; \quad \mu_{1}=\mu_{2}=4.44 ; \quad \mu_{0}=0.1 \quad\left(a_{1}=\mu_{1} / \mu_{2}=4.44 ; \quad a_{0}=\mu_{0} / \mu_{2}=0.0225\right) .
$$




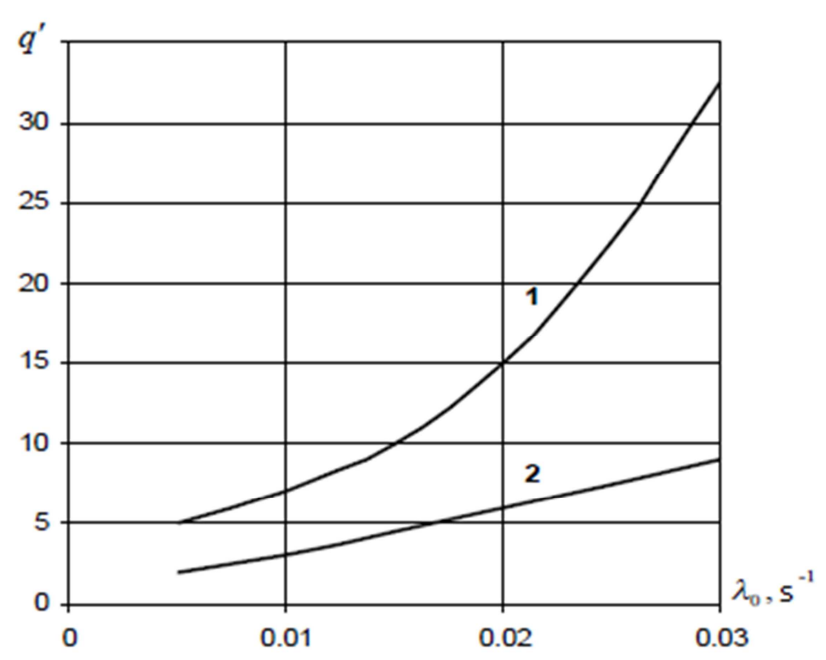

Fig. 2. Dependence of the length of the queues of the requests $\left(q^{\prime}\right)$ from the failures intensity $\left(\lambda_{0}\right)$.
The use of distributed web system always provides qualitative result of the calculation and provides the probability of operation in the conditions of its disintegration. In the process of DB operation with NoSQL interface the situation of the resources distribution in the web-system is automatically controlled.

Distributed web system provides availability and stability to partition. With NoSQL it is possible to get a reliable, high productive, flexible systems of data recovery. But such solution has a high price, because in the result of using NoSQL should be denormalized working DB, thereby complicating the logic of the application work, that is, to smooth transactions, work with "hard" data within the application etc.

\section{Conclusions}

Nowadays distributed computing web systems took priority place among high-productive computings and methods. With their development new concepts of the development of distributed systems are implemented, the tasks themselves are changed, organization information processes become easier, more simple methods of client resources use are developed. The technology of "cloud computing" provides a quality new economic level of integration of departmental systems and theirs resources in the web system.

The mathematical models that are investigated in the article allow to investigate various modes of computing organization in "the cloud computing" nodes, where each node is modeled by queueing system taking into consideration the effect of unproductive distractions of computational resources. Presented models for relative, absolute, mixed and combined priority service disciplines allowed us to obtain the final expressions for the desired service features of the web system. The combination of service discipline with one of the disciplines of the resumption of service has determined the conditions of priority systems separate tasks. Quantitatively the method of organization of the computational process can be evaluated by the following effectiveness indices by using the characteristics of the service.

[1] Carl Hewitt. ORGs for Scalable, Robust, Privacy-Friendly Client Cloud Computing. IEEE Internet Computing. 12, N. 5, 96-99 (2008).

[2] Foster I. The Anatomy of the Grid: Enabling Scalable Virtual Organizations. International Journal of High Performance Computing Applications. 15, N. 3, 200-222 (2001).

[3] Matov O. Ia. Information technology and the development of GRID systems in high-performance, globallydistributed computing infrastructures corporate cooperation. Registration, storage and processing of data. 6, N. 1, 85-98 (2004).

[4] GFD-I.080. Open Grid Services Architecture. Version 1.5. (2006).

[5] GrahamS. Building Web Services with Java: Making Sense of XML, SOAP, WSDL, and UDDI, SAMS (2005), 816 p.

[6] Foster I., Zhao Y., Raicu I, Lu S. Cloud computing and grid computing 360-degree compared, Grid Computing Environments Workshop, 2008, GCE'08., pp. 1-10 (2008).

[7] Matov O. Ia. Modern technologies of information resources integration. Registration, storage and processing of data. 11, N. 1, 33-42 (2009).

[8] Khramova I. O. The use of service-oriented architectures in the integration of information resources. Registration, storage and processing of data. 11, N. 2, 70-76 (2009). 
[9] Matov O. Ia. Mathematical models of conflict losses performance of the mediators ontology for General use in GRID environment. Registration, storage and processing of data. 11, N. 3, 18-25 (2009).

[10] Matov O. Ia. The problem of horizontal integration of information resources in a multi-tiered organizational structures with dynamic configuration. Registration, storage and processing of data. 9, N. 3, 88-97 (2007).

[11] Matov O. Ia. Dynamic integration of information resources of the unified information infrastructure of the electricity market. The functioning and development of electricity and gas markets: collection of scientific works Institute of modelling in energy im. H. Ie. Pukhova, 2006, pp. 93-98.

[12] Matov O. Ia. Model performance the operating nodes of the information infrastructure of corporate information systems in the field of electricity. Information technology in power engineering: collection of scientific works Institute of modelling in energy im. H. Ie. Pukhova, 2006, pp. 95-105.

[13] Matov O. Ia. The organization of ontologies in common use in the integrated information infrastructure preparation of data for decision-making. The functioning and development of electricity and gas markets: collection of scientific works Institute of modelling in energy im. H. Ie. Pukhova, 2006, pp. 99-103.

[14] Matov O. Ia. The problem of the use of GRID technologies as the basis of integration of information and analytical resources to support processes of electronic control. Proceedings of the Academy of engineering Sciences of Ukraine. N. 2 (2), 82-89 (2005).

[15] Boyko N. A look trough methods of intellectual data analysis and their applying in informational systems. Komp'yuterni nauky ta informatsiyni tekhnolohiyi CSIT 2016: Materialy XI Mizhnarodnoyi naukovotekhnichnoyi konferentsiyi CSIT 2016. L'viv: Vydavnytstvo L'vivs'koyi politekhniky, pp. 183-185 (2016).

[16] Boyko N. I. Tekhnolohiyi obrobky informatsiyi u dynamichnykh systemakh. Suchasni problemy prykladnoyi matematyky ta informatyky. Zbirnyk naukovykh prats'. L'viv: L'vivs'kyy natsional'nyy universytet imeni Ivana Franka, pp. 37-40 (2016).

\title{
Застосування математичних моделей для покращення організації інформаційних процесів у “хмарі"
}

\author{
Бойко Н. I. \\ Національний університет "Львівсъка політехніка" \\ вул. С. Бандери, 28а, 79013, Львів, Україна
}

\begin{abstract}
Подано основні підходи щодо організації розподіленого оброблення інформації в обчислювальних мережах і організації розподілених застосувань. Оглянуто основні підходи організації розподілених обчислювальних систем. Описано концепції GRIDобчислень, і виконано порівняльний аналіз технологій і архітектур побудови систем "хмарних обчислень" і GRID-систем. Наведено оцінки переваг та недоліків обчислювальних процесів у web-системах. Проаналізовано аналітичні моделі вузлів хмарних обчислень. Розглянуто нові концепції розвитку розподілених web-систем з використання NoSQL. Розглянуто основні методи організації процедур оброблення даних у розподілених мережах. Описано математичні моделі, які дають змогу вивчити спосіб організації обчислень у вузлах "хмари". Представлено моделювання роботи вузлів за допомогою публічних сервісів системи.
\end{abstract}

Ключові слова: інформачійна система, база даних, wеb-сервіс, хмарне обчислення, інформачійні потоки, інформачійні прочеси, оброблення даних.

2000 MSC: 94-06, 94A15, 94D05

удк: 519.72 